\title{
Intradialytic Hypertension and Associated Factors in Chronic Hemodialysis at the National Hemodidiadiasis Center in Donka, Guinea
}

\author{
Fousseny Diakité1* ${ }^{\circledR}$, Mamadou Saliou Baldé1, Alpha Koné2, Moussa Traoré1, Ibrahima Chérif1, \\ Alpha Boubacar Bah', Mohamed Tassilmy Diaby', Alpha Oumar Bah', Mohamed Lamine Kaba1 \\ ${ }^{1}$ Nephrology-Hemodialysis Service, Donka National Hospital, Conakry, Guinea \\ ${ }^{2}$ Service of Cardiology, National Hospital of Ignatius Deen, Conakry, Guinea \\ Email: ^fdiak70@gmail.com, ms2balde@yahoo.fr, alafekone@gmail.com, mousa11traore@gmail.com, icherif2@yahoo.fr, \\ bahalpha427@gmail.com,mohtasdia@gmail.com, bahalphaoumar1@gmail.com, kabalamin@yahoo.fr
}

How to cite this paper: Diakité, F., Baldé, M.S., Koné, A., Traoré, M., Chérif, I., Bah, A.B., Diaby, M.T., Bah, A.O. and Kaba, M.L. (2020) Intradialytic Hypertension and Associated Factors in Chronic Hemodialysis at the National Hemodidiadiasis Center in Donka, Guinea. Open Journal of Nephrology, 10, 34-42.

https://doi.org/10.4236/ojneph.2020.101005

Received: January 8, 2020

Accepted: February 22, 2020

Published: February 25, 2020

Copyright $\odot 2020$ by author(s) and Scientific Research Publishing Inc. This work is licensed under the Creative Commons Attribution International License (CC BY 4.0).

http://creativecommons.org/licenses/by/4.0/ (c) (i) Open Access

\begin{abstract}
Introduction: Dialytic high blood pressure (DHBP), although often ignored, is now recognized as a recurring and persistent phenomenon in a subgroup of hemodialysized patients. Its occurrence is associated with an increased risk of hospitalization and death. The objective of the study was to determine the prevalence of intradialytic hypertension and the factors associated with it. Methods: Study was cross-sectional, monocentric, descriptive and analytical over a three-month period from April 22 to July 22, 2019. Included were all patients 18 years of age or older, chronic hemodialysis for at least three months, with intra-dialytic high blood pressure. The blood pressure machine used for the majority of patients was an electronic "OMRON" blood pressure monitor. Epidemiological, clinical, para clinical and dialysis parameters were studied. The data were collected, captured and analyzed using IBM SPSS Statistics Version 20 software. The factors associated with intradialytic high blood pressure were searched using a univariate logistic regression model. The significance threshold for all statistical tests has been set at $5 \%$. Results: Of our 131 patients, 53 had intradialytic hypertension, a frequency of $40.5 \%$. The time of (DHBP) occurrence was more frequent at the 3rd and 2nd hour, $94.34 \%$ and $86.79 \%$, respectively. The average age of patients was 45.51 years with extremes ranging from 19 to 70 years. The average Systolic Blood Pressure (SBP) before dialysis was $148 \mathrm{~mm} \mathrm{Hg}-16.62$ and the average Diastolic Blood Pressure (DBP) before dialysis was $88 \mathrm{~mm} \mathrm{Hg}-12.50$. Pre-dialysis Blood Pressure-140/90 mm Hg was noted in 18 cases, or $34.0 \%$. The intradialytic average SBP was $164 \mathrm{~mm} \mathrm{Hg}-17.25$ with extremes of 121 to $202 \mathrm{~mm}$ $\mathrm{Hg}$. The intradialytic average DBP was $92 \mathrm{~mm} \mathrm{Hg}-12.52$ with extremes 67 to $124 \mathrm{~mm} \mathrm{Hg}$. The main risk factors associated with intradialytic hyperation
\end{abstract}


were: Age range (40 - 50 years), Duration on dialysis ( $<6$ months). Vascular nephropathy, hypoalbuminemia, Pre-dialytic Blood Pressure $\geq 140 / 90$ mmHg. BP post dialysis $\geq 165$, Dry weight $\geq 70 \mathrm{Kg}$, Number of antihypertensive agents $\geq$ Ultrafiltration rate $\geq 550 \mathrm{ml} / \mathrm{h}$. Conclusion: This study, the first of its kind in Guinea, was able to determine the frequency of intradialytic hypertension and the factors associated with it.

\section{Keywords}

Risk Factors, Intradialytic Hypertension, Donka Guinea

\section{Introduction}

High blood pressure, a common problem in chronic hemodialysis patients and high blood pressure variability, is a risk factor for high mortality [1]. Usually, in most chronic hemodialysis patients, blood pressure decreases during the hemodilysis session due to ultrafiltration (UF). However, in some patients, it increases and remains elevated during and after the dialysis session [2]. The definition of dialytic hypertension remains unclear and depends on the subjectivity of the authors who are interested in it. Most defined it as an increase in Systolic Blood Pressure (SBP) $-10 \mathrm{~mm} \mathrm{Hg}$ between pre-dialysis measurement and after dialysis [3]. The frequency of intradialytic hypertension varies according to the definition used [4]. Many reviews report a prevalence between 13.2\% and 33.9\% [5].

In the United States, in 2018, Assimon MM. et al., in a study of the frequency of intradialytic hypertension, reported $5 \%-20 \%$ of hemodialysis treatments [6].

In Italy, Losito A. et al. in 2016, reported a prevalence of 23.1\%. In Morocco in 2015 and in South Africa in 2016, the prevalence rates reported were respectively $29.17 \%$ and $28.4 \%$ [7].

Observational studies have shown that older age, lower dry weight, lower serum levels of creatinine and albumin, and the use of more antihypertensive drugs are associated with the occurrence of HID [8] [9] [10]. Our attention was drawn to the finding that, normotendus patients prior to dialysis and those controlled on pre-dialysis, developed intradialytic hypertension in per or post dialysis. The objective of the study was to determine the prevalence of intradialytic hypertension and the factors associated with it.

\section{Patients and Methods}

This was a cross-sectional, monocentric, descriptive and analytical study over a period of three (3) months from April 22 to July 22, 2019. It involved 131 chronic hemodialysis patients. All patients aged 18 years or older, chronic hemodialysis, have been included for at least three (3) months, with intra-dialytic high blood pressure. Patients were not included, patients: Having refused to participate in the study; Chronic hemodialysis not residing in Guinea, passing to the center; Acute kidney failure heshemodialysed. 
Data collection was manual on a data collection sheet. All epidemiological, clinical, para-clinical, and management data were collected on patient records and hemodialysis notebooks, supplemented by patient interrogation. For each patient, blood pressure was measured at: - $\mathrm{H} 0$ : Before plugging; - $\mathrm{H} 1$ : At $1 \mathrm{~h}$ of the connection; - $\mathrm{H} 2$ : At $2 \mathrm{~h}$ of the connection; - H3: At $3 \mathrm{~h}$ of the connection; -H4: At unconnection or sometimes without reaching the prescribed dialysis time, lying down or at possibly seated position. The voltage measurement device used for the majority of patients was an electronic "OMRON" blood pressure monitor isolated from NIPRO generators. A manual electronic "SANITAS" setter "SBM 42" type was used in 8 patients. Data Description: Were studied, the following parameters: epidemiological data: history and causal kidney disease, BP; BMI; weight; diuresis; vascular first, dialysis conductivity $(\mathrm{mS} / \mathrm{cm})$, seniority in hemodialysis, UF/h, duration of session, pace of sessions, interdialytic weight gain (PPID), and dose of dialysis expressed by (Kt/V). Intra-dialytic high blood pressure (HID) was defined as an increase of $10 \mathrm{~mm} \mathrm{Hg}$ of PAS during the dialysis session compared to that recorded at $\mathrm{H} 0$, with a recurrence of this phenomenon for at least 4 out of 6 sessions. The data was collected, captured and analyzed using IBM SPSS Statistics Version 20 software. Quantitative variables were expressed on average and in standard deviation. The qualitative variables were expressed in numbers and percentages. The factors associated with DHBP were researched using a univariate logistic regression model and dividing the study population into two (2) groups: -Group I, representing patients who met the DHBP definition criterion during the study period; -Group II, representing patients who did not meet the HID definition criterion during the study period, quantitative variables and percentage for qualitative variables. The Khi- 2 test was used for the comparison of qualitative variables and that of Anova (analysis of variance) for comparison between quantitative and qualitative variables. Pearson's correlation coefficient was calculated for the different variables studied. The significance threshold for all statistical tests has been set at $5 \%$. A P value of less than 0.05 was considered significant.

\section{Results}

Of our 131 patients, 53 had DHBP, representing a frequency of $40.5 \%$. The time of DHBP occurrence was more frequent at the 3rd and 2nd hour, 94.34 and $86.79 \%$, respectively. The average age of patients with DHBP was 45.51 years with extremes ranging from 19 - 70 years. The standard deviation was 15.83. Patients whose age was between [29 - 40] and [51 - 62] years were the most represented 19 cases (35.8\%) respectively. and 13 cases (24.5\%). The average hemodialysis duration was 23.51 months with extremes ranging from 3 to 156 months. The mode was 11 months and the median was 16 months. Patients with seniority between [12 - 24] months and those who had been on dialysis for at least 24 months were the most likely to be 22 cases (41.5\%) respectively. and 15 cases $(28.3 \%)$. 
Kidney disease was vascular in $41.5 \%$ of cases, followed by glomerular nephropathy with $30.2 \%$. Diabetic kidney disease was found in 8 patients or $15.1 \%$, tubulo-interstitial nephropathy and indeterminate kidney disease were present in 3 patients each, or 5.7\%. Finally, only one patient had hereditary kidney disease, or $1.9 \%$. The average SBP before dialysis was $148 \mathrm{~mm} \mathrm{Hg}$ with extremes ranging from 104 to $182 \mathrm{mmHg}$. The standard deviation was 16.62 . The average DBP before dialysis was $88 \mathrm{~mm} \mathrm{Hg}$ with extremes ranging from 66 to $114 \mathrm{~mm}$ Hg. The standard deviation was 12.50. Pre-dialysis PA-140/90 mm Hg was noted in 18 cases, or $34.0 \%$. The intradialytic average SBP was $164 \mathrm{~mm} \mathrm{Hg}$ with extremes ranging from 121 to $202 \mathrm{~mm} \mathrm{Hg}$. The standard deviation was 17.25. The intradialytic average DBP was $92 \mathrm{~mm} \mathrm{Hg}$ with extremes ranging from 67 to $124 \mathrm{~mm} \mathrm{Hg}$. The standard deviation was 12.52. The main risk factors associated with intradialytic hyperation were: Age range (40 - 50 years), Duration on dialysis ( $<6$ months)

Vascular nephropathy, hypoalbuminemia, Pre-dialytic Blood Pressure $\geq$ $140 / 90 \mathrm{mmHg}$.

BP post dialysis $\geq 165$, Dry weight $\geq 70 \mathrm{Kg}$, Number of antihypertensive agents $\geq$ Ultrafiltration rate $\geq 550 \mathrm{ml} / \mathrm{h}$.

Table 1 shows here that all our patients do 2 dialysis sessions per week and 4 hours per session. Intradialytic weight gain varies between 0 and $3 \mathrm{~kg}$.

Table 2 shows the main risk factors associated with intra-dialytic hypertension. Fifty-three of 131 patients had intra-dialytic hypertension.

\section{Discussion}

Of our 131 patients, 53 had Dialytic High Blood Pressure (DHBP), representing a frequency of $40.5 \%$. The time of DHBP occurrence was more frequent at the 3rd and 2nd hour, 94.34 and $86.79 \%$, respectively (Table 1).

The frequency of DHBP in our series was $40.5 \%$. This frequency is close to that found in a study conducted in Cameroon [5] which reported a frequency of $48.3 \%$, in Nigeria $45.3 \%$, and in the Philippines 37\% [11], but far higher than that found in the United States in 2018 with 5\% - 20\% of treatments hemodialysis [6]; Italy in 2016 with $23.1 \%$ [12]; South Africa $28.4 \%$ [13]. In Senegal, it was $22.6 \%$ [7]. In our study, the average age of patients was 45.51 years (Table 2).

Table 1. Breakdown of hemodialysis patients by dialysis parameters.

\begin{tabular}{ccccccc}
\hline & Minimum & Modus & Médian & Average & Maximum & $\begin{array}{c}\text { Standard } \\
\text { deviation }\end{array}$ \\
\hline Number session/week & 2 & & & & 2 & 0.000 \\
Number hours/week & 8 & & & & 8 & 0.000 \\
Intradialytic weight gain & 0 & 1 & 1 & 1.32 & 3 & 0.824 \\
Ultrafiltration/Hour & 120 & 500 & 420 & 433 & 860 & 205.160 \\
Conductivity & 137 & 140 & 140.05 & 139.91 & 143 & 1.901 \\
\hline
\end{tabular}


Table 2. Breakdown of hemodialysis by factors associated with intradialytic hypertension.

\begin{tabular}{cccc}
\hline \multirow{2}{*}{ Variables } & \multicolumn{3}{c}{ intradialytic Hypertension } \\
\cline { 2 - 4 } & Yes (53) & No (78) & P value \\
\hline Age range (40 - 50 ans) & $5(9.4 \%)$ & $18(23.1 \%)$ & 0.044 \\
Duration on dialysis (<6 months) & $4(7.5 \%)$ & $17(21.8 \%)$ & 0.029 \\
Vascular nephropathy & $22(41.5 \%)$ & $16(20.5 \%)$ & 0.009 \\
hypoalbuminemia & $12(71.0 \%)$ & $8(40.0 \%)$ & 0.036 \\
Pre-dialytic BP $\geq 140 / 90 \mathrm{mmHg}$ & $18(34.0 \%)$ & $44(56.4 \%)$ & 0.009 \\
BP post dialysis $\geq 165$ & $7(69.8 \%)$ & $37(47.4 \%)$ & 0.011 \\
Dry weight $\geq 70 \mathrm{Kg}$ & $6(11.8 \%)$ & $21(26.9 \%)$ & 0.030 \\
Number of antihypertensive agents $\geq$ & $48(90.6 \%)$ & $57(73.1 \%)$ & 0.006 \\
Ultrafiltration rate $\geq 550 \mathrm{ml} / \mathrm{h}$ & $14(26.4 \%)$ & $34(43.6 \%)$ & 0.045 \\
\hline
\end{tabular}

This result is different from those found by other authors; 50.69 - 13.89 years [5] and 38.0 - 5.9 [13], but much lower than that found in Greece $70.2-14.3$ years [14]. We found a statistically significant link $(p-0.044)$ between age and the occurrence of DHBP. Our result corroborates that reported by Patrice and Collar. Cameroon, which had found age as a factor associated with the occurrence of DHBP. Which would be at odds with those found by Okpa and Col. Nigeria [15], Labarcon and Bad-ang in the Philippines [11], and Van Buren and Col. Texas who had not found a statistically significant link. This finding could be explained in our series by the youngness of the Guinean population, but also by the shorter life expectancy of our population, which is 60.62 [16] years. Among patients with DHBP, men were the most represented 66.0\% ( $n-35)$ versus $33.9 \%(n-18)$ of women, or a sex ratio of 1.9 in favour of men (Text). This result is consistent with those found by Labarcon and Bad-ang in the Philippines [11] in 2015, Sebastian and Col. in South Africa in 2016 [13] and Okpa and Col. Nigeria in 2019 [15] who reported male predominance with a sex ratio of $1.1 ; 1.2$ and 1.2 respectively. Our results are identical to those reported by Moustapha and collar. Senegal [7] and Van Buren and Col. United States [17] who had found a sex ratio of 2 respectively. We did not find a statistically significant link between the occurrence of HID and gender $(p-0.820)$. The average hemodialysis duration in DHBP patients was 23.51 months -25.04 . Four patients (7.5\%) had done less than 6 months on dialysis in Group I versus 17 (21.8\%) Group II. We found a statistically significant link $(p-0.029)$. Our result is in line with that of Patrice and collar. who had also found dialysis duration as a factor associated with DHBP [5]. However, a duration of dialysis-30 months was considered a statistically associated factor $(p-0.001)$. Our result is at odds with those of Van Buren and Collet Shamir and col. [18] who had not found an association ( $p-0.9$ and $p-0.17$ respectively). The most observed kidney disease was vascular kidney disease with $41.5 \%(n-22)$ of cases. We found a statistically signifi- 
cant link ( $p-0.009)$. Our results are consistent with those found by Moustapha and collar. [7], Okpa and cervix who had also found a predominance of vascular kidney disease respectively $52.4 \%$ and $38.7 \%$. However, they did not find a statistically significant association with the occurrence of DHBP. This finding arouses the interest of the hypothesis of the role of endothelial cell dysfunction in the genesis of DHBP [19].

An hourly Ultrafiltration (UF) rate of $550 \mathrm{ml} / \mathrm{h}$ was observed in $26.4 \%$ of cases $(\mathrm{n}-14)$ and was statistically significant $(p-0.045)$ (Table 2$)$. Our result corroborates that of Patrice and collar. Who had found UF flow as a factor associated with DHBP. However, the flow of UF was $800 \mathrm{ml} / \mathrm{h}$ [5]. Our result is contrary to those reported by Sebastian and Collar. [13], Labarcon and Bad-ang, [11] as well as Van Buren and Col. [17] who did not find a correlation. This could be explained by the fact that a high flow of UF significantly reduces volemia and lowers BP [5]. In our study, patients in the DHBP group had a lower average inter dialytic weight gain (1.32 - 0.82 vs. 1.55 - 0.88$)$ than those in group II without noticing a statistically significant difference $(p-0.668)$ (Table 2$)$. This result corroborates those of Moustapha and col. Senegal [7] and Van Buren and Col. in 2016 [10], which had not also found a correlation. Our result is contrary to that found by Shamir and collar. United States, which had found a statistically significant correlation ( $p-0.001)$ [18]. The average pre-dialytic SBP of DHBP patients was $148 \mathrm{~mm} \mathrm{Hg}$-17. The average pre-dialytic DBP was $88 \mathrm{~mm} \mathrm{Hg}-12$. Pre-dialysis BP-140/90 mm Hg was rated in 34.0\% ( $\mathrm{n}-18$ ) of patients in Group I versus 44 patients, or $56.4 \%$ in Group II. We found a statistically significant link $(p-0.012)$. Our results are similar to those found by Patrice and collar. [6] and Moustapha and collar [7], who had found a systolic-diastolic Arterial Hypertension as a factor associated with a value $p-0.001$ and $p-0.004$ respectively.

The average dry weight was 57.91 - $9.63 \mathrm{~kg}$ in Group I compared to $62.57 \mathrm{~kg}$ 14.93 in Group II. 6 DHBP patients were rated as a dry weight of $70 \mathrm{~kg}$, or $11.76 \%$ compared to 21 patients (26.92\%) Group II. We found a statistically significant correlation $(p-0.030)$. Our results are similar with those of Patrice and collar. [5] Who had found dry weight as a factor associated with DHBP. However, the dry weight was $67 \mathrm{~kg}(p-0.001)$. Our results are at odds with those of Eftimovska and Col. [6] and Van Buren and collar. [17] Who had not found an association ( $p-0.521$ and $p-0.2$ respectively). She was informed in 17 cases (32.1\%). The average was $32.9 \mathrm{~g} / \mathrm{l}$ compared to $36.7 \mathrm{~g} / \mathrm{dL}$ in Group II. More than half (70.6\%) DHBP patients had hypo albuminemia versus $40 \%$ in Group II. We found a statistically significant link $(p-0.036)$. Our results are consistent with those reported in the literature and with those of Moustapha and collar. [7], and Labarcon and Bad-ang [8], who had found hypo albuminemia peripheral vascular resistance [8]; on the other hand, because these patients are more prone to malnutrition and generally drink more fluids. Fifty (94.3\%) DHBP patients were on antihypertensive therapy. Of these, $48(96 \%)$ used at least one dual therapy. We found a statistically significant link $(p-0.006)$. Our results corroborate 
Table 3. Distribution of hemodialysis patients according to predictive factors of DHBP.

\begin{tabular}{cccc}
\hline Variables & RR & IC $=95 \%$ & P value \\
\hline Age group (40 - 50 ans) & 0.49 & $0.22-1.09$ & 0.044 \\
Duration of dialysis (<6 mois) & 0.43 & $0.17-1.06$ & 0.029 \\
Vascularis nephropathy & 1.74 & $1.17-2.59$ & 0.009 \\
Hypoalbuminia & 2.4 & $0.95-6.03$ & 0.036 \\
BP pré-dialytic $\geq \mathbf{1 4 0 / 9 0 ~} \mathbf{m m H g}$ & 0.57 & $0.36-0.90$ & 0.009 \\
BP post dialytic $\geq \mathbf{1 6 5}$ & 2.07 & $1.12-3.82$ & 0.011 \\
Dry weight $\geq \mathbf{7 0 ~} \mathbf{~ g ~}$ & 0.49 & $0.23-1.03$ & 0.030 \\
Number of antihypertension $\geq$ & 2.86 & $1.14-7.18$ & 0.006 \\
Ultrafiltration rate $\geq \mathbf{5 5 0 ~} \mathbf{m l} / \mathbf{h}$ & 0.62 & $0.38-1.02$ & 0.045 \\
\hline
\end{tabular}

those of Patrice and col. [5] who had also found an association with the use of a number of antihypertensive drugs $-2(p .0 .001)$. This could be explained by the fact that patients with a large number of antihypertensive drugs are most often those with high hemodynamic instability.

Following a one-varied logistic regression model, the factors that increased the risk of DHBP occurring were: A post-dialysis PP $65 \mathrm{~mm} \mathrm{Hg}$; Vascular kidney disease; Hypo albuminemia; and the use of a number of antihypertensives. Factors associated with lower risk were: the 40 - 50 age group; A flow of UF-550 $\mathrm{ml} / \mathrm{h}$; dialysis duration-6 months; A pre-dialysis BP-140/90 mm Hg; and a dry weight of $70 \mathrm{~kg}$ (Table 3 ).

\section{Conclusion}

This study, the first of its kind in Guinea, was able to determine the frequency of intradialytic hypertension and the factors associated with it. An upcoming study would be interested in managing these predictors of intradialytic hypertension.

\section{Conflicts of Interest}

All authors have read and approved the manuscript. They declare that there is no conflict of interest related to this work.

\section{References}

[1] Van Buren, P.N. and Inrig, J.K. (2016) Mechanisms and Treatment of Intradialytic Hypertension. Blood Purification, 41, 188-193. https://doi.org/10.1159/000441313

[2] Cirit, M., Akçiçek, F., Terzioglu, E., Soydas, C., Ok, E., Ozbasli, C.F., et al. (1995) "Paradoxical" Rise in Blood Pressure during Ultrafiltration in Dialysis Patients. Nephrology Dialysis Transplantation, 10, 1417-1420. https://doi.org/10.2174/1573402111208040282

[3] AbdulRahim, N. and Molony, D.A. (2012) Intradialytic Hypertension: An Under-Recognized Cardiovascular Risk Factor. What Is the Evidence? Current Hypertension Reviews, 8, 282-290.

[4] Georgianos, P.I., Sarafidis, P.A. and Zoccali, C. (2015) Intradialysis Hypertension in 
End-Stage Renal Disease Patients: Clinical Epidemiology, Pathogenesis, and Treatment. Hypertension, 66, 456-463.

https://doi.org/10.1161/HYPERTENSIONAHA.115.05858

[5] Patrice, H.M., Loïc, B.E., Hermine, F., Pierre, N.M.J., Denis, T., François, K.F., et al. (2018) Intradialytic Hypertension and Associated Factors among Chronic Haemodialysed Patients in Sub-Saharan Africa: An Example from Cameroon. Open Journal of Nephrology, 8, 105-116. https://doi.org/10.4236/ojneph.2018.84012

[6] Assimon, M.M., Wang, L. and Flythe, J.E. (2018) Intradialytic Hypertension Frequency and Short-Term Clinical Outcomes among Individuals Receiving Maintenance Hemodialysis. American Journal of Hypertension, 31, 329-339.

https://doi.org/10.1093/ajh/hpx186

[7] Moustapha, F., Tall, L.A., Yaya, K., Moustapha, C.M., Mohamed, S.S., Maria, F., et al. (2018) Intradialytic Hypertension: Prevalence and Associated Factors in Chronic Hemodialysis Patients in Senegal. Open Journal of Nephrology, 8, 29-37. https://doi.org/10.4236/ojneph.2018.82004

[8] Inrig, J.K. (2010) Intradialytic Hypertension: A Less-Recognized Cardiovascular Complication of Hemodialysis. American Journal of Kidney Diseases, 55, 580-589. https://doi.org/10.1053/j.ajkd.2009.08.013

[9] Meyring-Wösten, A., Luo, Y., Zhang, H., Preciado, P., Thijssen, S., Wang, Y., et al. (2018) Intradialytic Hypertension Is Associated with Low Intradialytic Arterial Oxygen saturation. Nephrology Dialysis Transplantation, 33, 1040-1045. https://doi.org/10.1093/ndt/gfx309

[10] Eftimovska-Otovic, N., Grozdanovski, R., Taneva, B. and Stojceva-Taneva, O. (2015) Clinical Characteristics of Patients with Intradialytic Hypertension. PRILOZI, 36, 187-193. https://doi.org/10.1515/prilozi-2015-0066

[11] Labarcon, K.A. and Bad-ang, M.T.L. (2018) Predictors of Intradialytic Hypertension in Chronic End Stage Renal Dialysis Patients in a Tertiary Government Hospital in Davao City. Journal of Clinical Nephrology and Therapeutics, 2, 15-27. https://doi.org/10.35841/clinical-nephrology.2.1.14-26

[12] Losito, A., Del Vecchio, L., Del Rosso, G. and Locatelli, F. (2016) Postdialysis Hypertension: Associated Factors, Patient Profiles, and Cardiovascular Mortality. American Journal of Hypertension, 29, 684-689. https://doi.org/10.1093/ajh/hpv162

[13] Sebastian, S., Filmalter, C., Harvey, J. and Chothia, M.-Y. (2016) Intradialytic Hypertension during Chronic Haemodialysis and Subclinical Fluid Overload Assessed by Bioimpedance Spectroscopy. Clinical Kidney Journal, 9, 636-643. https://doi.org/10.1093/ckj/sfw052

[14] Raikou, V.D. and Kyriaki, D. (2018) The Association between Intradialytic Hypertension and Metabolic Disorders in End Stage Renal Disease. International Journal of Hypertension, 2018, Article ID: 1681056. https://doi.org/10.1155/2018/1681056

[15] Okpa, H.O., Effa, E.E., Oparah, S.K., Chikezie, J.A., Bisong, E.M., Mbu, P.N., et al. (2019) Intradialysis Blood Pressure Changes among Chronic Kidney Disease Patients on Maintenance Haemodialysis in a Tertiary Hospital South-South Nigeria: A 2 Year Retrospective Study. Pan African Medical Journal, 33, 91. https://doi.org/10.11604/pamj.2019.33.91.17000

[16] Guinée-Espérance de vie à la naissance (année). Statistiques [Internet]. http://perspective.usherbrooke.ca/bilan/tend/GIN/fr/SP.DYN.LE00.IN.html

[17] Van Buren, P.N., Zhou, Y., Neyra, J.A., Xiao, G., Vongpatanasin, W., Inrig, J., et al. (2016) Extracellular Volume Overload and Increased Vasoconstriction in Patients With Recurrent Intradialytic Hypertension. Kidney and Blood Pressure Research, 
41, 802-814. https://doi.org/10.1159/000450565

[18] Shamir, A.R., Karembelkar, A., Yabes, J., Yao, Y., Miskulin, D., Gassman, J., et al. (2018) Association of Intradialytic Hypertension with Left Ventricular Mass in Hypertensive Hemodialysis Patients Enrolled in the Blood Pressure in Dialysis (BID) Study. Kidney and Blood Pressure Research, 43, 882-892.

https://doi.org/10.1159/000490336

[19] El-Shafey, E.M., El-Nagar, G.F., Selim, M.F., El-Sorogy, H.A. and Sabry, A.A. (2008) Is There a Role for Endothelin-1 in the Hemodynamic Changes during Hemodialysis? Clinical and Experimental Nephrology, 12, 370-375.

https://doi.org/10.1007/s10157-008-0065-2 